\title{
DNA methylation dynamics during ex vivo differentiation and maturation of human dendritic cells
}

Xue Zhang ${ }^{1 \dagger}$, Ashley Ulm² ${ }^{2 \dagger}$, Hari K Somineni ${ }^{2 \dagger}$, Sunghee $\mathrm{Oh}^{3}$, Matthew T Weirauch ${ }^{4}$, Hong-Xuan Zhang ${ }^{5}$, Xiaoting Chen ${ }^{6}$, Maria A Lehn ${ }^{7}$, Edith M Janssen ${ }^{7}$ and Hong $\mathrm{Ji}^{2^{*}}$

\begin{abstract}
Background: Dendritic cells (DCs) are important mediators of innate and adaptive immune responses, but the gene networks governing their lineage differentiation and maturation are poorly understood. To gain insight into the mechanisms that promote human DC differentiation and contribute to the acquisition of their functional phenotypes, we performed genome-wide base-resolution mapping of 5-methylcytosine in purified monocytes and in monocyte-derived immature and mature DCs.

Results: DC development and maturation were associated with a great loss of DNA methylation across many regions, most of which occurs at predicted enhancers and binding sites for known transcription factors affiliated with DC lineage specification and response to immune stimuli. In addition, we discovered novel genes that may contribute to DC differentiation and maturation. Interestingly, many genes close to demethylated CG sites were upregulated in expression. We observed dynamic changes in the expression of TET2, DNMT1, DNMT3A and DNMT3B coupled with temporal locus-specific demethylation, providing possible mechanisms accounting for the dramatic loss in DNA methylation.

Conclusions: Our study is the first to map DNA methylation changes during human DC differentiation and maturation in purified cell populations and will greatly enhance the understanding of DC development and maturation and aid in the development of more efficacious DC-based therapeutic strategies.
\end{abstract}

Keywords: DNA methylation, Human dendritic cells, Monocytes, Differentiation, Maturation, TET, DNMT

\section{Background}

Dendritic cells (DCs) are a heterogeneous group of bone marrow-derived cells within various organs, which display different cell surface phenotypes and serve different functions depending on location, development, and activation status. DCs bridge two arms of the immune response: the innate immune response via the recognition of pathogens through pattern-recognition receptors and the adaptive immune response via the activation of $\mathrm{T}$ and $\mathrm{B}$ cells [1]. They can exist in two developmental states, immature (iDC) and mature (mDC), with alternate functional characteristics in each state. The induction of DC differentiation

\footnotetext{
* Correspondence: Hong.Ji@cchmc.org

${ }^{\dagger}$ Equal contributors

${ }^{2}$ Division of Asthma Research, Cincinnati Children's Hospital Medical Center, 3333 Burnet Ave, Cincinnati, OH 45229, USA

Full list of author information is available at the end of the article
}

ex vivo from human and mouse peripheral monocytes by granulocyte-macrophage colony stimulating factor (GM-CSF) and Interleukin 4 (IL4) suggest that monocytes may serve as an important reservoir for DC development [2]. Mouse studies also support that monocytes can develop in vivo into a DC-like population [3]. Like conventional DCs (cDCs), GM-CSF and IL-4 derived DCs (iDCs) upregulate their expression of CD11c and major histocompatibility complex (MHC) class II complexes and efficiently stimulate naive T cells [4]. A widely accepted cytokine mix can further transform iDCs into mDCs [5]. With the FDA approval of the antigen-presenting cell vaccine sipuleucel-T for prostate cancer, DC-based therapeutic vaccines have become an established approach for the treatment of established cancer. In human blood, two major phenotypically and functionally distinct DC 
populations have been described, the $\mathrm{CD} 11 \mathrm{c}^{+} \mathrm{CD} 123^{-}$ myeloid DCs and the CD11c ${ }^{-} \mathrm{CD} 123^{+}$plasmatoid DCs. The myeloid DCs have been further defined into three subsets based on the expression of CD16, BDCA-1 and BDCA-3 [6]. Recently, it has been demonstrated that human $\mathrm{BDCA}^{+} \mathrm{DCs}$ possess characteristics of mouse $\mathrm{CD} 8 \alpha^{+} \mathrm{DCs}$ and can induce cytotoxic T lymphocyte responses $[7,8]$, and therefore, are the most relevant targets for vaccination against cancer. Due to the complexity of the lineage and difficulty in lineage determination based on surface markers, the molecular mechanisms regulating the development of DCs are not well understood compared to other lineages such as T cells [9]. Studying the ex vivo differentiation of monocytes into DCs may help us better understand the differentiation of different DC subtypes in vivo and allow for the successful generation of more efficacious DC vaccines in the future.

As an epigenetic mechanism that regulates gene expression both in cis and in trans, DNA methylation has been shown to regulate gene expression of related pathways and cellular identity in the immune system [10-13]. In mammalian cells, DNA methylation is maintained by DNA methyl-transferases DNMT1, DNMT3A and 3B. DNMT1 methylates hemi-methylated parent-daughter duplexes during DNA replication, while de novo methylation is predominantly carried out by DNMT3A and 3B. Several promising, yet controversial, mechanisms have been proposed for DNA demethylation, such as the deamination of $5 \mathrm{mC}$ to $\mathrm{T}$, coupled with $\mathrm{G} / \mathrm{T}$ mismatch repair by DNA glycosylases [14], or the hydroxylation of TET proteins through the generation of 5-hydroxymethylcytosine $(5 \mathrm{hmC})$ and 5-formylcytosine $(5 \mathrm{fC})$ [15-17]. The combination of methylation by DNMTs and demethylation by TETs may contribute to the observed dynamic DNA methylation changes during cellular differentiation [10]. DNA methylation is a potential mechanism governing the differentiation and activation of DCs. Indeed, locus and region-specific DNA methylation changes have been observed during the ex vivo differentiation of monocytes to iDCs $[12,18]$. A detailed study of DNA methylation dynamics during these processes will greatly help to better tease apart the molecular events that occur during the transition from monocytes to iDCs, and from iDCs to mDCs.

In this study, we established genomic maps of DNA methylation at single nucleotide-resolution for human monocytes and monocyte-derived immature and mature DCs [19]. Besides identification of genes and pathways known to be involved in DC differentiation and maturation, we observed dynamic DNA methylation changes at many novel genes, most of which are demethylated. Interestingly, these changes occur close to the binding sites of transcription factors that are implicated in DC differentiation and function. In addition, we correlated
DNA methylation levels at differentially methylated sites/points (DMPs) with expression levels of genes located within 1,500 bp distance using published gene expression arrays and found a general inverse correlation between DNA methylation and gene expression levels. Time course experiments showed that the demethylation event is locus-specific, and is coupled with dynamic changes in the DNA methylation machinery, including TET2, DNMT1, DNMT3A and DNMT3B. Besides providing detailed DNA methylome reference maps for purified monocytes, iDCs and mDCs, our study demonstrated the dynamic epigenetic regulation of genes and pathways important for DC development and maturation, which are potential targets to improve DC-based therapeutic strategies.

\section{Results}

Genome-wide scanning identifies DNA methylation changes during dendritic cell differentiation and maturation

We ex vivo differentiated monocytes (from four blood donors) into iDCs and matured them using the Jonuleit cytokine cocktail mix (IL-1 $\beta$, IL-1 $\alpha$, IL-6, TNF- $\alpha$ and $\mathrm{PGE}_{2}$ ) following the established FDA approved protocol [see Additional file 1A] [5]. The iDCs (HLA-DR ${ }^{\text {low }}$ ) and mDCs $\left(\mathrm{CD}^{+} 3^{+}, \mathrm{CD}^{+} 6^{+}\right.$and HLA-DR $\left.{ }^{\text {high }}\right)$ were fluorescence-activated cell sorting (FACS) purified ( $>95 \%$ purity) and subjected to further analysis [see Additional file 1B]. Using a cutoff of $P$ value $\leq 0.05$ and absolute difference $\geq 0.1$, we identified 1,608 DMPs from monocytes to iDCs and 156 DMPs from iDC to mDCs (Table 1, Figure $1 \mathrm{~A}$ and $\mathrm{B})$. Only $6 \%$ of the identified DMPs are located within $\mathrm{CpG}$ islands even though $31 \%$ of CG sites assayed are within CpG islands. Consistent with previous observations, our findings support that the DNA methylation level of CGs at shores and shelves (defined as regions that are 0 to $2 \mathrm{~kb}$ and 2 to $4 \mathrm{~kb}$ away from $\mathrm{CpG}$ islands, respectively) may be more dynamic and critical during cellular differentiation than that of $\mathrm{CpG}$ islands [10]. Interestingly, the vast majority of these sites are demethylated (1,367 out of 1,608 DMPs from monocytes to iDC and 139 out of 156 DMPs from iDC to $\mathrm{mDC}$ ) (Figure 1 and Table 1). We further measured whole-genome DNA methylation levels using an ELISA-based method, and confirmed the occurrence of CG demethylation during iDC differentiation from monocytes (Figure 1C). A total of 933 genes are linked to the 1,608 DMPs with DNA methylation changes from monocytes to iDCs (Table 1). Among these genes, 795 genes are exclusively linked to demethylated DMPs, 117 genes are linked to more methylated DMPs, and 21 genes (2\%) are linked to DMPs with methylation changes in both directions [see Additional file 2A, B and C]. A total of 116 genes are linked to the $156 \mathrm{DMPs}$ from iDC to mDCs, among which 102 genes are linked to DMPs, all with 
Table 1 Numbers of differentially methylated CG sites (DMPs) identified during ex vivo dendritic differentiation and maturation

\begin{tabular}{|c|c|c|c|c|c|c|c|c|c|}
\hline \multirow[t]{2}{*}{ Comparisons (G1 versus G2) } & \multicolumn{2}{|c|}{$\begin{array}{l}\text { Numbers } \\
\text { of DMPs }\end{array}$} & \multicolumn{4}{|c|}{$\begin{array}{l}\text { Locations of DMPs } \\
\text { relative to CpG islands (\%) }\end{array}$} & \multirow[t]{2}{*}{$\begin{array}{c}\text { Enhancer } \\
\text { associated }^{\mathrm{e}}\end{array}$} & \multirow[t]{2}{*}{$\begin{array}{l}\text { Promoter } \\
\text { associated }^{f}\end{array}$} & \multirow[t]{2}{*}{$\begin{array}{c}\text { Gene } \\
\text { associated }^{\mathrm{g}}\end{array}$} \\
\hline & G1 > G2 & $\mathbf{G 1}<\mathrm{G} 2$ & Islands & Shores $^{b}$ & Shelf ${ }^{c}$ & $>4 \mathrm{~kb}^{\mathrm{d}}$ & & & \\
\hline $\mathrm{CD}_{14^{+}}$versus immature dendritic cell (iDC) & 1368 & 240 & 5.9 & 23.5 & 16.1 & 54.5 & 701 & 139 & 933 \\
\hline iDC versus mature dendritic cell (mDC) & 139 & 17 & 3.3 & 18.2 & 14.9 & 63.6 & 80 & 9 & 116 \\
\hline
\end{tabular}

${ }^{a} P$ value cutoff of 0.05 , difference change of $10 \%$ in DNA methylation was used to calculate the number of DMPs (see Methods).

${ }^{\mathrm{b}}$ Shores were defined for this table as $2 \mathrm{~kb}$ from an island ( $\mathrm{N}$ and $\mathrm{S}$ island).

'Shelves were defined for this table as $2 \mathrm{~kb}-4 \mathrm{~kb}$ away from an island ( $\mathrm{N}$ and $\mathrm{S}$ shore).

${ }^{\mathrm{d}}$ Regions over $4 \mathrm{~kb}$ from an island.

e, f, g Based on HumanMethylation450 v1.2 Manifest File (http://support.illumina.com/downloads/infinium_humanmethylation450_product_files.html).

reduced methylation, and the rest of 14 genes are linked to DMPs, all with increased methylation [see Additional file $2 \mathrm{D}$ and $\mathrm{E}$.

A great number of the identified demethylated CG sites are located at enhancers (Table 1, 43.6\% CG sites from monocyte to iDCs and $51.6 \%$ from iDC to $\mathrm{mDC}$ ). Previous studies have shown that chromatin markers including $\mathrm{H} 3 \mathrm{~K} 4 \mathrm{me} 1, \mathrm{H} 3 \mathrm{~K} 4 \mathrm{me} 3$ and $\mathrm{H} 3 \mathrm{~K} 27 \mathrm{Ac}$ are enriched at human enhancers [20,21] and are highly cell-type specific. We examined the overlap between H3K4me1, H3K4me3 and H3K27Ac markers in monocytes [22] with CG sites that undergo DNA methylation changes from monocyte to iDCs, and found that $67.6 \%$ of the CG sites have H3K4me1 markers (45.5\% $\mathrm{CG}$ sites from iDC to $\mathrm{mDC}$ ). More than half of these CG sites with H3K4me1 also have H3K4me3 and H3K27Ac markers.

We then searched for transcription factor binding sites in 51 bp windows centered on these DMPs and identified several transcription factors with known roles in dendritic cell lineage specification (Figure 1D, Additional file 3, see Methods). The consensus sequence of the most strongly enriched motif for the monocyte to iDC transition is TGACTGA, the AP-1 response element bound by bZIP transcription factors JUN, FOS, BATF, BATF3, as well as IRF4, and IRF8 [23]. Among these, IRF8 is a transcription factor that distinguishes a DCcommitted progenitor from myeloid progenitors [24] and is important for the development of several DC subsets $[25,26]$. In addition, BATF3 binds to JUN and is required for the normal development of $\mathrm{CD} 8 \alpha^{+} \mathrm{cDCs}$ in mouse models and BDCA3 $3^{+}$DCs in humans [27-29]. Furthermore, IRF4 interacts with PU.1 and is required for the development of $\mathrm{CD} 11 \mathrm{~b}^{+} \mathrm{cDCs}$ [30]. Motifs most strongly enriched for the iDC to $\mathrm{mDC}$ transition contain a GGAA core, which binds to transcription factors including BCL11A, SPIB and RELA. Indeed, BCLLA and SPIB may regulate pDC development [31,32], while RELA is a NF- $\kappa B$ family member that regulates CD11c ${ }^{+}$ DC generation [33] and cytokine production in myeloid DCs [34].
Pathway analysis reveals significant genes and networks during dendritic cell differentiation

We next performed pathway analysis to identify biological processes that undergo DNA methylation changes during DC differentiation and maturation, stratified by directions of change [see Additional files 4 and 5]. First, components of the IL-4 and GM-CSF signaling pathways were demethylated, consistent with our approaches and suggesting that these molecules induce DC differentiation from monocytes through the modification of DNA methylation. The genes involved in cytokine production and interaction with T cells, such as IL-6, IL-10, IL-12 and T cell receptor signaling were demethylated when exposed to differentiation stimuli [see Additional file $4 \mathrm{~A}$ ], indicating an epigenetic priming of iDCs by IL-4 and GM-CSF for their secretion of cytokines and activation of naïve $\mathrm{T}$ cells.. Consistently, upstream regulator analysis in Ingenuity Pathway Analysis (IPA) revealed that targets of IL- $1 \alpha$, IL- $1 \beta$, IL- 6 and TNF- $\alpha$ are differentially methylated in iDCs by IL-4 and GM-CSF induction [see Additional file 6]. These cytokines are included in the DC maturation cocktail, supporting a priming process for the response of the immature DCs to cytokine stimuli.

Second, an IPA search on demethylated genes from monocytes to iDCs [see Additional file 2A] resulted in a number of enriched pathways including Aryl Hydrocarbon Receptor signaling (AhR), PPAR signaling, AKT signaling, Integrin signaling, IL-6 signaling, IL-10 signaling, IL-12 signaling and production, T cell receptor signaling, NRF2mediated oxidative stress response, granulocyte adhesion and diapedesis, caveolae-mediated endocytosis signaling, clathrin-mediated endocytosis signaling, and macropinocytosis signaling (Figure 2A and Additional file 4A). Interestingly, many of these demethylated pathways are required for DCs to recognize and process antigens and present them to $\mathrm{T}$ cells, which is in line with the functional characteristics of iDCs (Figure 2A). For example, $S R C$ (Rous sarcoma oncogene) encodes a tyrosine-protein kinase that participates in many immune pathways. Proteins encoded by $S R C$, AHRR (aryl-hydrocarbon receptor repressor), and CYP1B1 (cytochrome P450, family 1, 


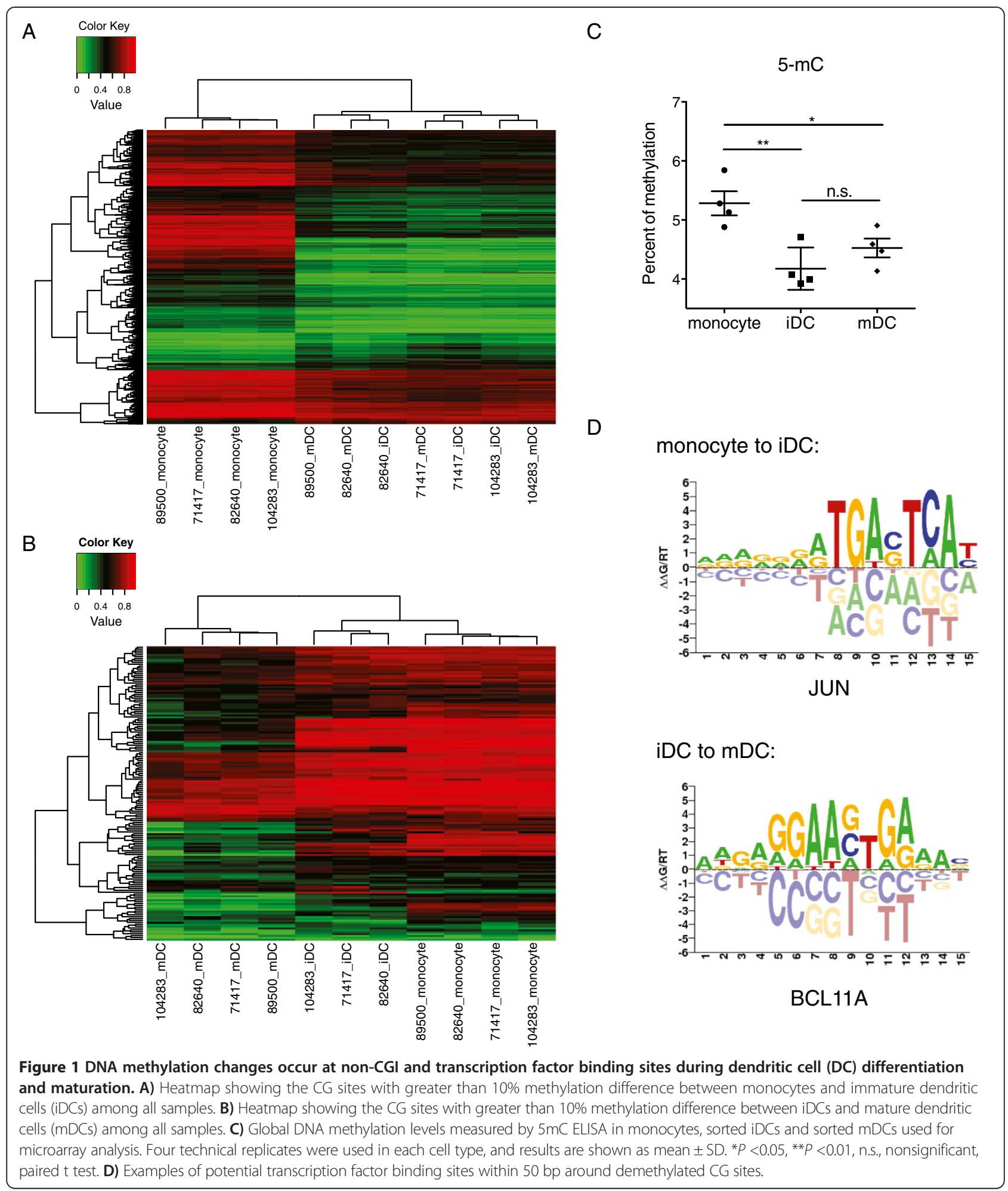

subfamily B, polypeptide 1) participate in the AhR signaling cascade, which mediates the response of DCs to dioxin [35-37], and is involved in the regulation of normal immune cell development and the immune response of DCs following lipopolysaccharide challenge or influenza virus infection [38,39]. PPARG (peroxisome proliferator-activated receptor gamma) encodes a lipidactivated transcription factor that positively regulates 


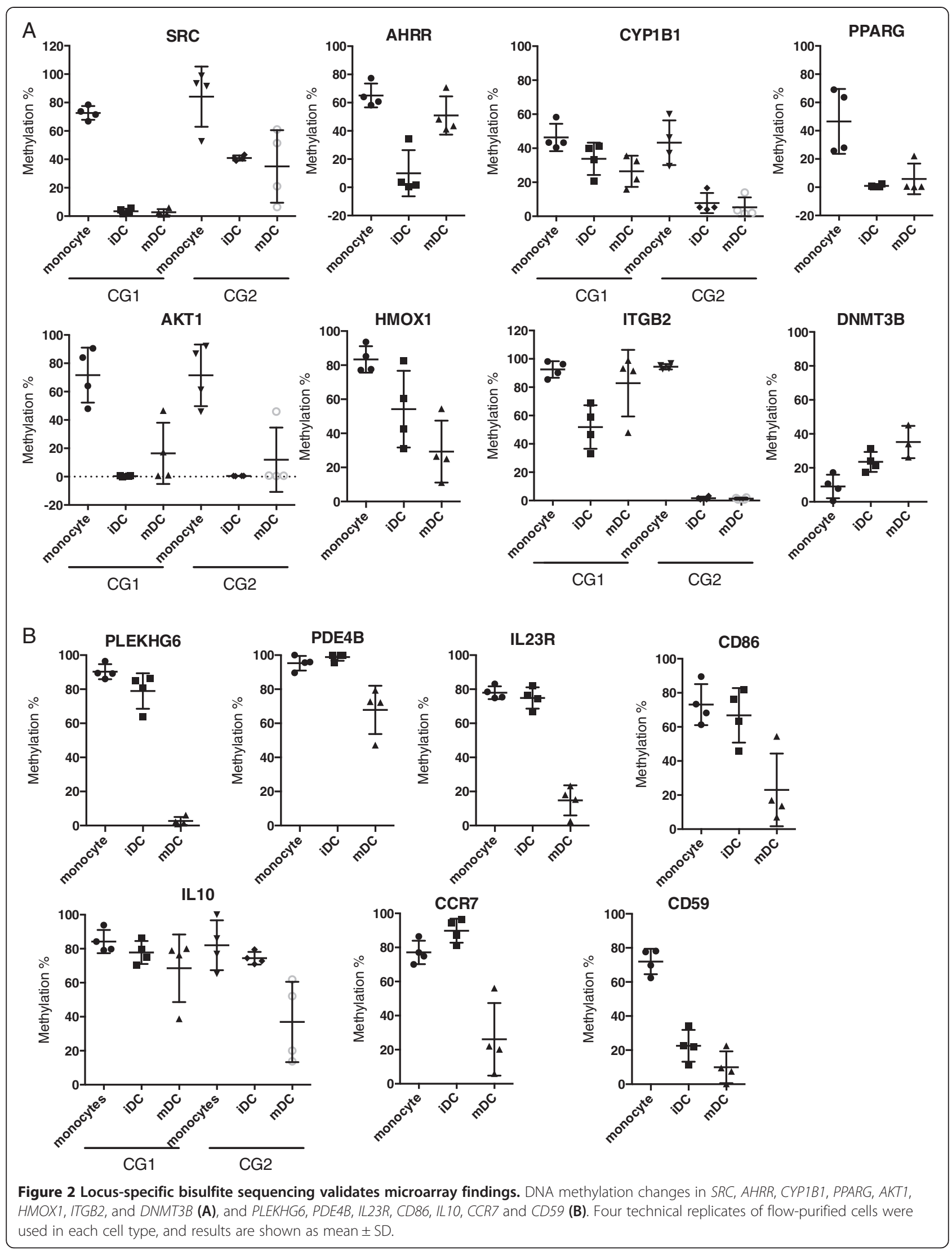


myeloid DC maturation and functions [40-43]. However, the detailed roles of each of the genes in DC differentiation and maturation are unclear. We also observed an $80 \%$ decrease in DNA methylation at a CG site located within the second intron of $A K T 1$ (v-akt murine thymoma viral oncogene homolog 1). AKT plays a critical role in proinflammatory-mediated DC survival and maturation; human monocyte-derived DCs with constitutively active lipid raft-targeted AKT1 survived significantly longer and had promoted antigen-specific T-cell responses, while downregulation of $A K T 1$ reduced their life span [44]. In addition, the methylation level at a CG site located at the 3' UTR of HMOX1 (heme oxygenase 1) was found to be reduced. The heme oxygenase 1 (HO-1) encoded by this gene is a stress responsive gene whose expression is induced by a variety of stimuli including heme, heavy metals, inflammatory cytokines, and nitric oxide (reviewed in [45]). Induction of $\mathrm{HO}-1$ inhibits lipopolysaccharide (LPS)-induced dendritic cell phenotypic maturation and the secretion of proinflammatory cytokines, resulting in the inhibition of alloreactive T-cell proliferation $[46,47]$. The activation of these genes is consistent with the role of iDC in taking up antigens by phagocytosis or macropinocytosis and processing the internalized antigen.

\section{Pathway analysis reveals significant genes and networks during dendritic cell maturation}

From $\mathrm{iDC}$ to $\mathrm{mDC}$, the pathways involved in communication between innate and adaptive immune cells, the complement system, and cross talk between DCs and natural killer cells were demethylated [see Additional file 5A]. This is consistent with the function of $\mathrm{mDC}$ in antigen presentation to effector cells through the expression of MHC and membrane-associated co-stimulatory molecules, and secretion of co-stimulatory cytokines. Specifically, we found that CG sites located in myosin-interacting guanine nucleotide exchange factor (PLEKHG6), phosphodiesterase 4B (PDE4B), interleukin 23 receptor (IL23R), CD86, interleukin 10 (IL10) and chemokine receptor 7 (CCR7), and CD59 were significantly demethylated from iDC to $\mathrm{mDC}$ (Figure 2B). Among these genes, the expression of $P D E 4 B$ is low in iDCs and is upregulated in mDCs (GSE7509) [48], which is consistent with its high methylation in iDCs and reduced DNA methylation level in mDCs. Addition of PDE4 inhibitor during DC maturation impairs IL12 and TNF- $\alpha$ production in response to LPS and CD40 ligand and destroys the capacity to generate Th1 cells [49]. IL23R encodes interleukin-23 receptor, which pairs with IL12RB1 to form the receptor for IL-23A/IL-23. This receptor is expressed in T cells, and IL-23A signaling is required for the survival and/or expansion of Th17 cells [50]. Although this protein is also expressed on monocyte-derived DCs (GSE6965) [51], the role of IL23R in DC maturation and function is unknown. Further, CD86 is a surface marker for DCs, and binding of this protein to CD28 acts as a co-stimulatory signal for T cell activation by DCs $[52,53]$. The methylation at a CG site located in the IL10 promoter is reduced in mDCs compared to iDCs. IL10 may regulate DC differentiation and maturation because addition of IL10 to the differentiation cocktail generates $\mathrm{mDCs}$ with distinct phenotypes [54] and these DCs have an impaired capacity to induce a Th1-type response in vivo, leading to the development of Th2 lymphocytes [55]. CCR7 is a chemokine receptor necessary to direct dendritic cells (DCs) to secondary lymphoid nodes and to elicit an adaptive immune response [56-58]. Similarly, as a cell surface glycoprotein that regulates complement-mediated cell lysis, CD59 is constitutively expressed in monocyte derived-DCs. However, how this protein regulates DC function is not clear. Maturation by LPS or TNF- $\alpha / \mathrm{IL}-1 / \mathrm{PGE}_{2}$ significantly increases CD59 expression [59], probably through demethylation of the promoter of CD59 as suggested by our study.

\section{DNA methylation changes are correlated with gene expression profiles}

DNA methylation provides a mechanism for robust and epigenetically heritable gene silencing. DNA methylation at $\mathrm{CpG}$ islands has been the focus of many studies and is generally associated with gene silencing. However, significant methylation changes do not occur exclusively at CpG islands. CpG island shores and shelves are also closely associated with transcriptional silencing $[10,60,61]$. To further understand the role of observed DNA methylation changes, we correlated our DNA methylation data with publically available gene expression data (Affymetrix Human genome U133 Plus 2) for monocytes, iDCs and mDCs (GEO: GSE7509) [48,62]. In general, we found a significant negative correlation between DNA methylation and gene expression at differentially methylated loci from monocytes to iDCs at $\mathrm{CpG}$ shores, shelves and open sea (Figure 3). This is in agreement with previous findings in hematopoietic lineage commitment, and highlights the significance of DNA methylation in gene silencing. Several validated demethylated CG sites are associated with a significant increase in gene expression (Figure 3). From iDCs to mDCs, there is a similar relationship between DNA methylation and gene expression, although none of them reached statistical significance likely due to the smaller number in each category [see Additional file 7].

\section{Expression of DNA methylation machinery couples with dynamic DNA methylation changes}

Among the DMPs we discovered, we have observed extensive demethylation during monocyte differentiation into iDCs and from iDCs to mDCs (Table 1, Figure 1A and B). One of the mechanisms that could account for this 


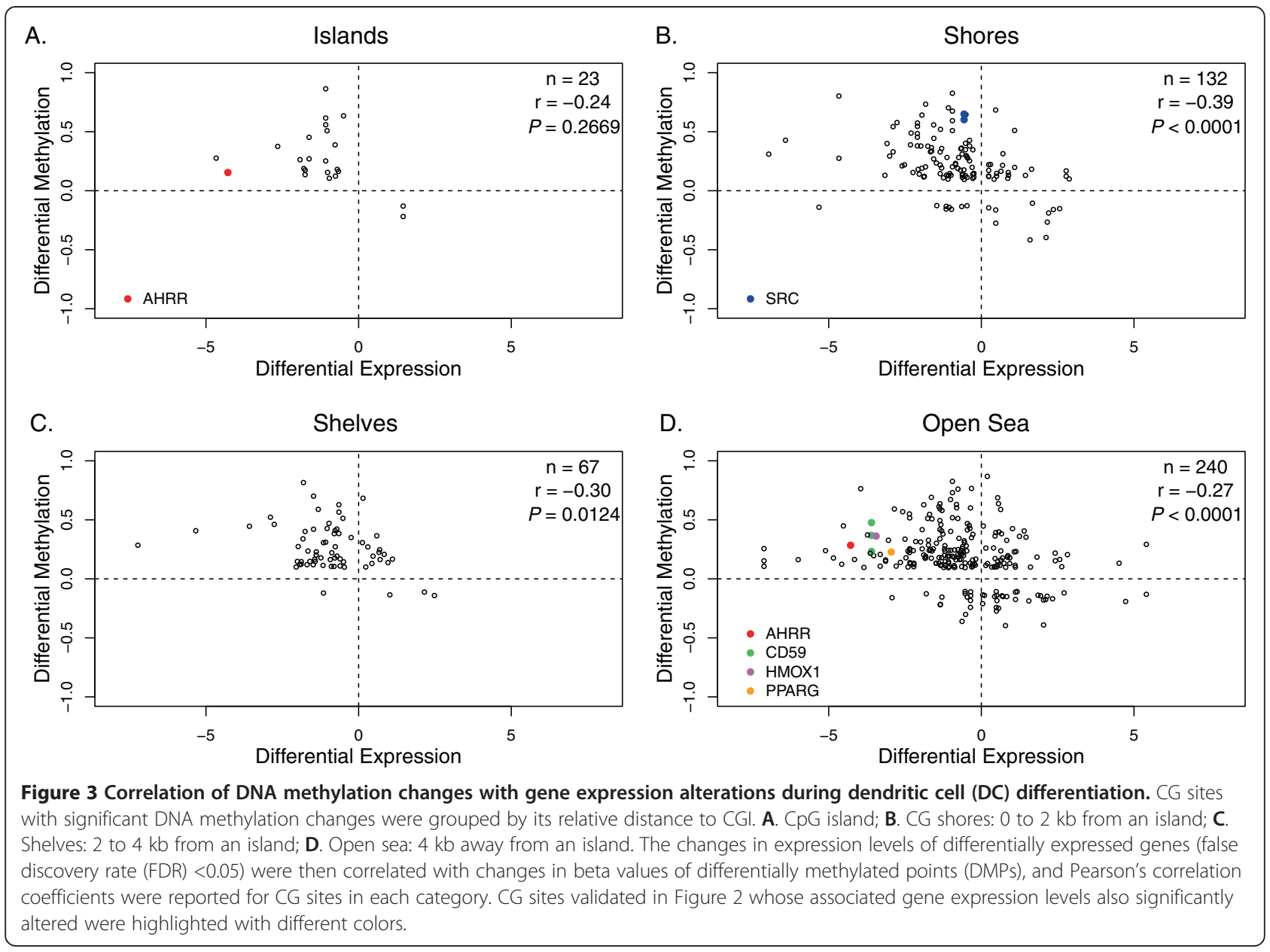

demethylation is the downregulation of DNA methyltransferases, including DNMT1, DNMT3A and DNMT3B. Surprisingly, independent analyses of monocytes, iDCs and $\mathrm{mDCs}$ generated from individual donors showed a significant increase in the expression levels of DNMT1 and $D N M T 3 A$ during the differentiation from monocyte to iDC (day 1 to 4 versus day 0 ) and a significant decrease at 24 hours after the addition of maturation cocktail (mature day-1 versus day-4) [see Additional file 8A]. However, the later significance with $D N M T 3 A$ was lost when we analyzed pooled data from four individual donors, possibly due to the variability between donors (Figure 4A). The respective increase and decrease in the expression levels of DNMT1 during differentiation and maturation was in agreement with the previously published dataset (GEO: GSE7509). However, our finding of DNMT3A during the differentiation of monocyte to iDC contradicts the public dataset, where they reported a significant decrease. In addition, our time-course experiments found a novel and significant upregulation of DNMT3B 48 hours after the addition of the maturation cocktail (mature day-2) (Figure 4 and Additional file 8A). Collectively, our data suggest de novo methylation upon the initiation of differentiation and demethylation upon the initiation of maturation, followed by de novo methylation during maturation.

Another mechanism for active demethylation is TET protein-mediated oxidation of $5 \mathrm{mC}$ to $5 \mathrm{hmC}$, a potential intermediate for active DNA demethylation, followed by secondary reactions that eventually lead to restoration of cytosine. The expression of TET1 was very low and there was no detectable change during the course of this experiment. However, the expression levels of TET2 were highly upregulated as early as day 1 during monocyte to iDC differentiation (Figure $4 \mathrm{~B}$ and Additional file $8 \mathrm{~B})$. The expression of TET3 remained unchanged during the differentiation as well as maturation (Figure $4 \mathrm{~B}$ ). It has been previously shown that region-specific demethylation by TET protein through the production of $5 \mathrm{hmC}$ is promoted by PPAR $\gamma$-induced PARylation in adipocytes [63]. Indeed, we found that many components within the PPAR $\gamma$ pathway, including PPAR $\gamma$ itself, were demethylated from monocyte to iDC (Figure 2A), suggesting that this pathway might also be involved in DC differentiation.

To further examine the temporal dynamics of DNA methylation changes, we used an ELISA-based methodology 


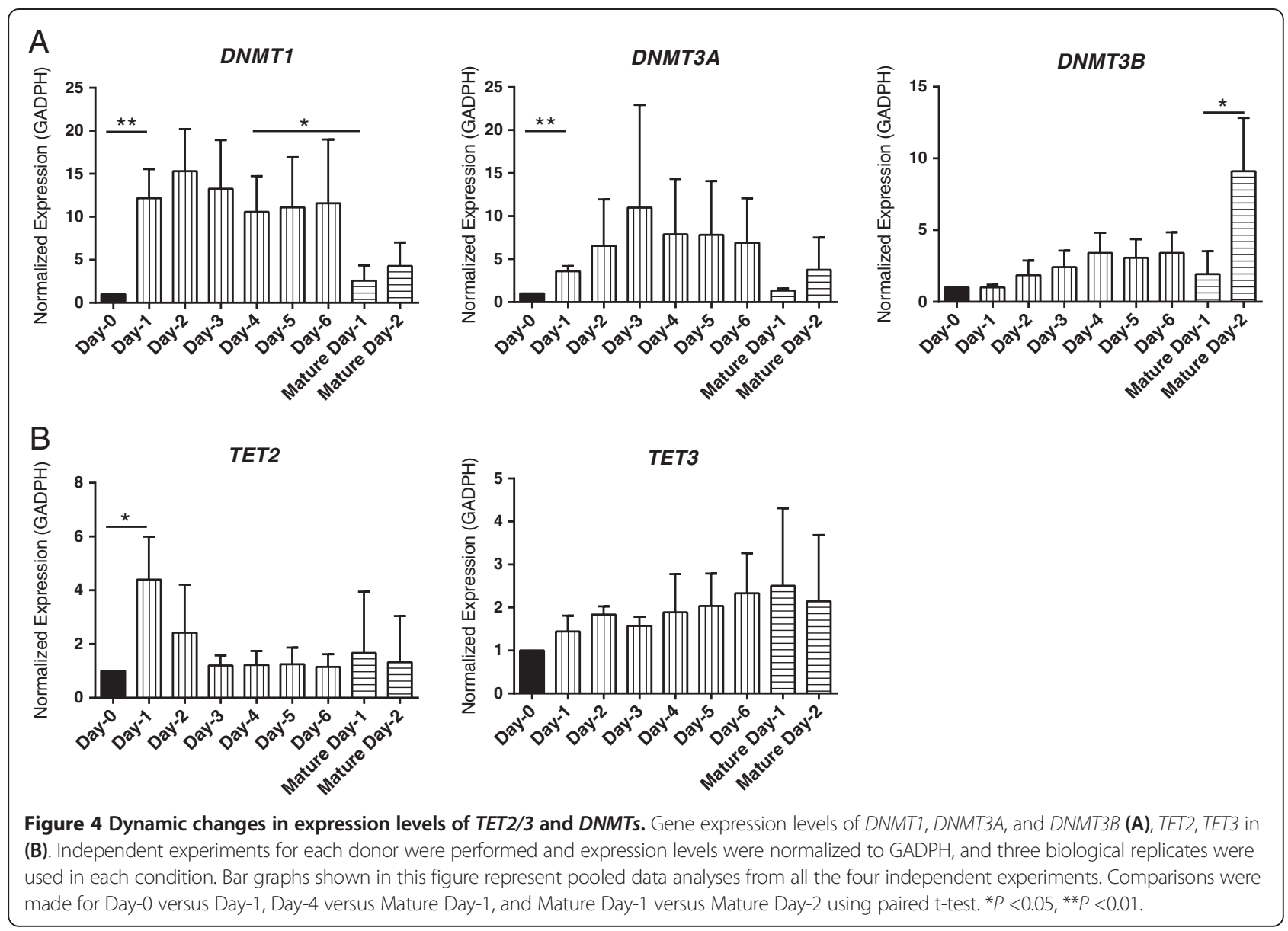

to examine global 5-mC and 5-hmC level dynamics during the course of monocyte differentiation and iDC maturation. We observed a trend of loss in gross levels of $5 \mathrm{mC}$ during the course of differentiation [see Additional file $9 \mathrm{~A}$, day-0 to day-4], consistent with what we have observed in purified cell populations. However, after the addition of maturation cocktail, there was a significant reduction in global $5 \mathrm{mC}(P=0.044$, mature day- 1 versus day-4), followed by a trend of increase. This coincides with the upregulation of TETs and DNMTs, suggesting that TETs and DNMTs may be responsible for the dynamic changes in DNA methylation. However, the level of $5 \mathrm{hmC}$ was not significantly altered during DC differentiation although there was a trend of loss during maturation [see Additional file $9 \mathrm{~B}, P=0.052$ ]. Parallel analysis of purified monocytes, iDCs and mDCs with this same approach also showed no significant changes in global $5 \mathrm{hmC}$ level [see Additional file 9C].

\section{Gene-specific demethylation dynamics regulate expression profiles}

In order to better characterize the gene- and locus-specific early and late methylation modifications, we measured the methylation level at specific CG sites in SRC, PLEKHG6 and ITGB2, which showed a huge erasure of DNA methylation (approximately $70 \%$ to $80 \%$ ) either from monocytes to iDCs or from iDCs to mDCs during this time course. The two CG sites in $S R C$ were demethylated as early as 24 hours after the addition of IL-4 and GM-CSF and stayed the same for rest of the experiment, suggesting that demethylation of this gene is an early active event in DC differentiation (Figure 5A). This demethylation was associated with significant upregulation of $S R C$ expression at 24 hours (Figure 5B), consistent with previous reports (GSE7509, Figure $3 B$ ). This change in DNA methylation couples with an increase in the expression of DNMT1, DNMT3A, and TET2 (Figure 4). In contrast, the CG site located at the 5' UTR of PLEKHG6 was gradually demethylated with IL-4 and GM-CSF treatment, and was completely demethylated after the addition of the maturation cocktail, suggesting that the erasure was more of a passive, steady process occurring over a period of time. It is likely that the demethylation in PLEKHG6 does not directly regulate gene expression, because, despite the differences in DNA methylation dynamics in SRC and PLEKHG6, their expression dynamics are similar (Figure 5A and B). The expression of $S R C$ and 


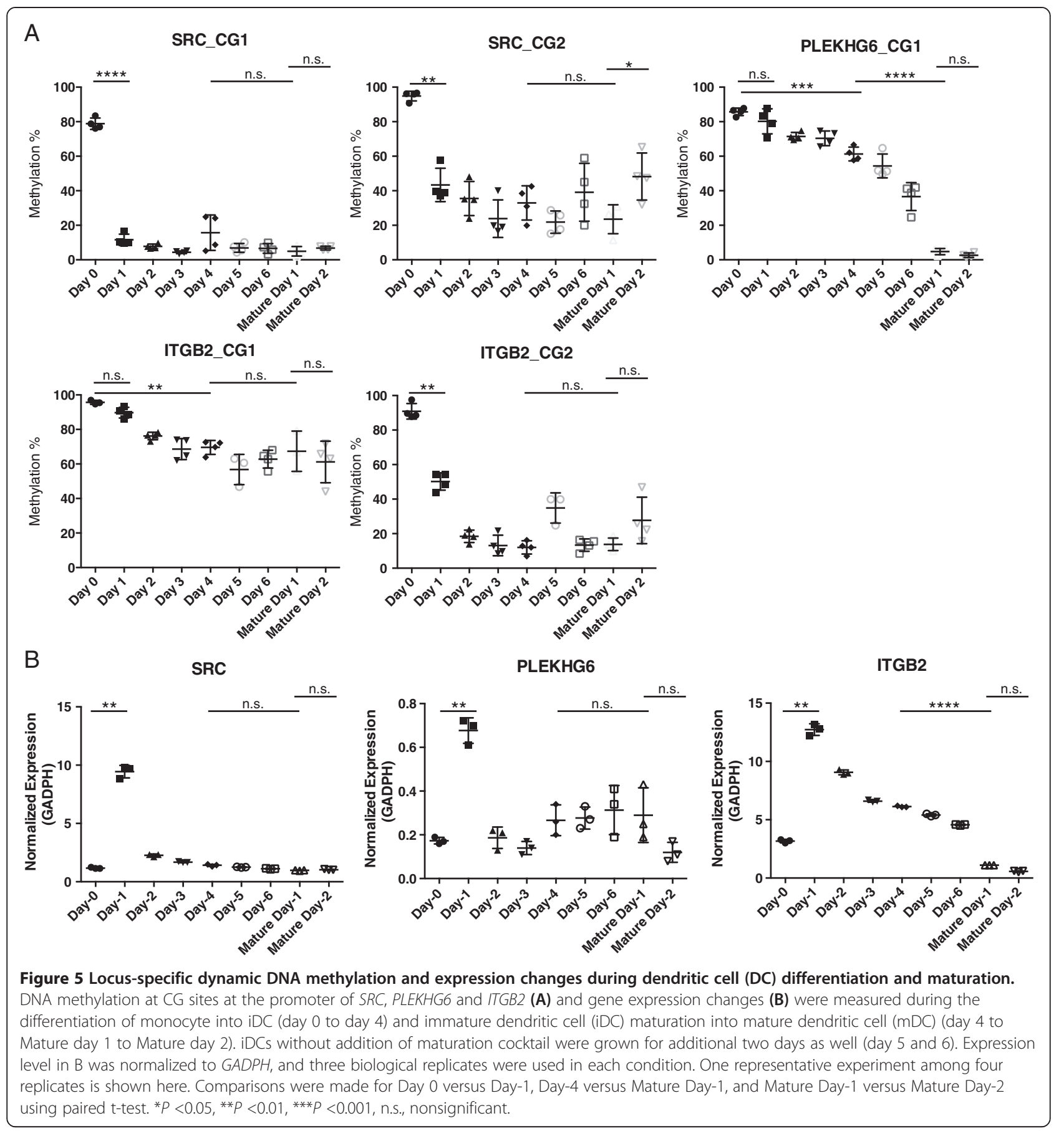

PLEKHG6 went down to basal levels after 48 hours and remained almost constant for the rest of the experiment, similar to previous reports (GEO: GSE7509) (Figure 5B). The methylation level of two CG sites in ITGB2 (CG1 and CG2) was reduced to a stable level in 2 days (Figure $5 \mathrm{~A}$ ). However, the demethylation of CG1 is much slower than CG2, and the change of CG2 is more associated with the rapid regulation of ITGB2 at 24 hours (Figure 5B). Consistent with the published dataset (GSE7509), the expression of ITGB2 was significantly upregulated during the differentiation of monocytes into iDCs, and was significantly downregulated during their maturation. Collectively, our observations demonstrated that the alteration of DNA methylation for these CG sites does not occur at the same time, and their impacts on gene expression may differ. This suggests delicate, time-specific epigenetic programming during development and possibly site-specific mechanisms for DNA demethylation. 


\section{Discussion}

In order to enhance our understanding of DNA methylation in DC lineage commitment and cellular response to external stimuli, we established single nucleotide-resolution genome-wide and locus-specific DNA methylation studies for $\mathrm{CD}_{1} 4^{+}$monocytes, monocyte-derived dendritic cells (iDCs), and DCs matured by Jonuleit cocktail (mDCs). Dynamic DNA methylation changes, predominately an erasure of DNA methylation, occurred during these two ex vivo processes, particularly around enhancers and binding sites for transcription factors known for dendritic cell lineage specification. Besides the identification of previously studied genes and pathways involved in dendritic cell function, our analysis also revealed many novel candidate genes, which are likely important for dendritic cell differentiation and response to stimuli. A negative correlation between methylation changes at CG sites and the expression of nearby genes was found independent of the location of CG sites, suggesting interplay between these two regulatory mechanisms. Time-course studies of enzymes involved in DNA methylation maintenance revealed dynamic changes in the expression level of TET2, DNMT1, DNMT3A and $D N M T 3 B$ during differentiation and maturation, indicating that these enzymes may account for such function-specific and location-specific variations in DNA methylation.

\section{Our analysis reveals novel candidates involved in dendritic cell (DC) differentiation and maturation}

Dendritic cells are antigen-presenting cells that excel at activating naïve T-cells, and in their steady state they act as sentinels that detect pathogens. When activated by these pathogens, they initiate the body's innate and adaptive immune responses through the secretion of cytokines along with the presentation of antigenic peptides on MHCs. The functions of the known genes detected in our analyses are consistent with the functional switch of DCs between the steady and activated states (Figure 2). In addition, we were able to uncover many novel candidate genes for studying DC differentiation and activation. One candidate is PLEKHG6, a gene that encodes a guanine nucleotide exchange factor that can activate small GTPase RHOG and RAC1, and form a complex with ezrin and MYH10. Ezrin recruits PLEKHG6 to the apical pole of epithelial cells, where PLEKHG6 induces the formation of microvilli and membrane ruffles [64]; this interaction between PLEKHG6 and ezrin is required for EGF-stimulated macropinocytosis. PLEKHG6 can also form a complex with MYH10 and RHOA, which is located at the cleavage furrow to advance furrow ingression during cytokinesis $[65,66]$. To date, no studies have addressed the role of PLEKHG6 in dendritic cell maturation. However, our observations of greatly reduced methylation levels at a CG site at the 5'-UTR of PLEKHG6 as well as at CG sites in the $5^{\prime}$-UTR of its interacting partner RHOG, and the second intron of MYH1O suggest that this complex may play a role in the acquisition of functions that are associated with a more mature DC phenotype $[67,68]$. Additionally, the methylation level at a CG site located at the 5'UTR of ITGB2 (beta 2 integrin, which encodes integrin beta chain beta 2) was reduced by $74 \%$ (Figure 2A). The integrin beta chain beta 2 combines with the alpha L chain to form the integrin LFA-1, and combines with the alpha $M$ chain to form the integrin Mac-1. LFA-1 play a central role in leukocyte ( $\mathrm{T}$ cells) migration across blood vessel walls into lymph nodes and tissues, and it is a key participant in the immunological synapse $[69,70]$. However, the detailed role of LFA-1 in dendritic cell is not clear.

\section{TET2 and DNMTs may be responsible for the spatial and temporal DNA methylation changes}

We observed that over 1,367 CG sites underwent demethylation from monocytes to iDCs, and 139 CG sites were demethylated during the transition from iDCs to mDCs. Detailed locus-specific DNA methylation measurement by pyrosequencing found that these methylation changes were locus- and time-specific (Figure 2 and Figure 5). Recently, it has been shown that TET2 is highly expressed during monocyte differentiation and is required for active demethylation from monocytes to iDCs [71]. However, in this study, the expression of TET2 (normalized to HPRT) remained nearly constant for 66 hours [71]. In contrast, we noticed a significant increase in the expression of $T E T 2$, as early as 24 hours after the introduction of IL-4 and GM-CSF. As the upregulation of TET2 remained significant, even after normalizing with HPRT in our experiments [see Additional file 8D], this disparity could be due to the difference in the concentrations of IL-4 and GM-CSF used to generate iDCs. Further, siRNAmediated knockdown of TET2 in monocytes prevented active demethylation at specific loci during monocyte differentiation [71], which supports our observation that TET2 expression is upregulated when demethylation occurs. In addition, a study conducted by Kallin et al. reported that TET2 binds to the promoter of ITGB2 during myeloid transdifferentiation and knockdown of TET2 was associated with an incomplete activation of ITGB2 [72], which is in line with our observation, supporting that TET2 may influence ITGB2 expression through promoter demethylation. In agreement with the previous reports, levels of TET1 were undetectable, and furthermore, and no differences were observed in TET3 expression levels, suggesting TET2 as an important player in the erasure of DNA methylation during the differentiation of monocyte into iDCs.

Surprisingly, we observed significantly increased expression of DNMT1 and DNMT3A upon the initiation of monocyte differentiation to iDCs, and significant 
downregulation of DNMT1 upon maturation, followed by significant upregulation of $D N M T 3 B$ during the maturation of iDCs to mDCs. DNMT1 is responsible for the maintenance of DNA methylation through mitotic divisions, while DNMT3A/3B are de novo methyltransferases that actively methylate DNA during multiple cellular processes [73-75]. It has been shown that knocking down DNMT1 and DNMT3B or inhibition by azacytidine results in global demethylation [76]. Controversially, DNMTs were also proposed to function as deaminases and base excision enzymes to reduce DNA methylation [14,77]. Recently it has also been shown that DNMTs are capable of directly removing the hydroxymethyl moiety from $5-\mathrm{hmC}$ and the methyl group from $5-\mathrm{mC}$ in vitro or in a redox state-dependent manner $[78,79]$. Therefore, it is tempting to speculate that DNMTs have a dual role in regulating DNA methylation. They could actively demethylate DNA or de novo methylate DNA. Interestingly, the methylation level of a CG site located at the $5^{\prime}$ UTR of DNMT3B showed a gradual increase, suggesting that the expression of DNMT3B might also be regulated by DNA methylation (Figure 2A). Although inhibitors of DNMTs did not affect the active DNA methylation process during iDC formation [18], mDCs generated with DNMT inhibitors during iDC differentiation and maturation exhibited differences in surface marker expression and cytokine production [80], suggesting a possible regulatory role of DNMTs on some specific genes. Nevertheless, our data strongly support further investigation on the exact roles of DNMTs in DC differentiation and maturation, possibly on an individual gene basis at a specific timing.

\section{Clinical implications and future directions}

Our studies suggest that DNA methylation regulates key genes and pathways in dendritic cell differentiation and maturation. The feasibility of large-scale ex vivo generation of DCs from patients' monocytes allows for therapeutic application of ex vivo-cultured DCs to bypass the dysfunction of endogenous DCs, restore immune surveillance, induce cancer regression and stabilization, and delay or prevent its recurrence. While the most common paradigm of the therapeutic application of DCs reflects their use as cancer 'vaccines', additional and potentially more effective possibilities include the use of patients' autologous DCs as part of more comprehensive therapies. This involves in vivo or ex vivo induction of tumor-reactive $\mathrm{T}$ cells, which would counteract systemic and local immunosuppression in tumor-bearing hosts. Given the reversibility of DNA methylation by demethylating reagents and the possibility of gene-specific DNA manipulation using long non-coding RNA [81], our observations suggest a novel approach to regulate this process. Ex vivo-cultured DCs can therefore be instructed to acquire distinct and optimal functions relevant to the induction of effective cancer immunity (DC polarization), such as the induction of different effector functions or different homing properties of tumor-specific T cells. Our data also support a possible role for TET enzymes and DNMTs in DC differentiation and maturation, suggesting that both could be targeted to modify the treatment efficacy of DC vaccines.

\section{Conclusions}

Locus- and time-specific DNA demethylation occurs during the ex vivo differentiation of human monocytes into immature dendritic cells and their maturation by an FDA-approved cytokine cocktail. Many of such DNA methylation changes happen near promoters, enhancers and transcriptional factor binding sites, and are correlated with an increase in gene expression of nearby genes. Importantly, the expression level of TET2, DNMT1, DNMT3A and $D N M T 3 B$ are upregulated in a time-dependent manner, which happens concurrently with the DNA methylation changes, suggesting that these enzymes may be responsible for the precise spatial and temporal regulation of DNA methylation levels.

\section{Methods}

\section{Ex vivo generation and maturation of dendritic cells}

This study was approved by Cincinnati Children's Hospital Medical Center (CCHMC) Institutional Review Board and characterized as not human subject research (CCHMC, IRB \#2012-0136). Peripheral Blood Mononuclear Cells (PBMCs) were isolated from the blood samples of anonymous healthy donors from the Hoxworth Blood center at University of Cincinnati using Ficoll-Paque Plus density gradient centrifugation. Monocytes were then isolated from PBMCs by $\mathrm{CD}_{1} 4^{+}$sorting with Miltenyi beads (Miltenyi Biotec Inc., San Diego, CA, USA) and cultured in the presence of GM-CSF $(1000 \mathrm{U} / \mathrm{ml})$ and IL-4 $(500 \mathrm{U} / \mathrm{ml})$ for 4 days to induce differentiation into mostly immature monocyte-derived DCs (iDCs) [82-85]. These DCs were matured by culturing for an additional two days in the presence of a Jonuleit cocktail (IL1 $\beta$, IL1 $\alpha$, IL6, TNF $\alpha$ and PGE2) [5]. Harvested cells were sorted to obtain pure populations of the desired cell, before being subjected to DNA methylation analysis using microarrays and pyrosequencing. Cells used in the time-course experiment were directly subjected to DNA/RNA extraction.

\section{Flow cytometry}

Immature DCs and mature DCs were stained with a LIVE/DEAD Fixable Dead Cell Stain Kit (Life Technologies, Grand Island, NY, USA), then fixed with 2\% PFA. After fixation, the cells and appropriate controls were prepared. All samples were stained with HLA-DR-PE/Cy7 (Biolegend, San Diego, CA, USA), CD83-AF647 (Biolegend, San Diego, CA, USA), and CD83-PE (Biolegend, San Diego, 
CA, USA). Cells were analyzed on a BD LSR II (BD Biosciences, San Jose, CA, USA). Flow data were analyzed using FlowJo v9.6.1 software.

\section{Cell sorting}

CD14 ${ }^{+}$cells presorted by CD14 MicroBead Kit (Miltenyi Biotec Inc., San Diego, CA, USA), immature DCs, and mature DCs were stained with CD14-FITC (Biolegend, San Diego, CA, USA), HLA-DR-PE/Cy7 (Biolegend, San Diego, CA, USA), CD83-AF647 (Biolegend, San Diego, CA, USA) and Live/Dead-7-AAD (eBioscience, San Diego, CA) and sorted on a MoFlo XDP (Beckman Coulter Inc., Brea, CA, USA). Cells were collected in 100\% FBS and pelleted for DNA/RNA extraction.

\section{DNA and RNA isolation}

DNA and RNA were isolated from the same samples using AllPrep DNA/RNA Micro kit (Qiagen, Valencia, CA, USA) according to the manufacturer's protocols.

\section{Illumina Infinium $450 \mathrm{~K}$ beadchip DNA methylation analysis}

Genomic DNA was bisulfite treated and assayed by the Illumina Infinium HumanMethylation450 BeadChip (Illumina, San Diego, CA, USA) at the Genomics and Microarray lab at University of Cincinnati Medical Center. Quality of the arrays was assessed using sampleindependent and dependent internal control probes included on the array for staining, extension, hybridization, specificity and bisulfite conversion. One immature DC sample exhibited low intensity for all controls, suggesting a problematic quality of this array. Therefore, this sample was excluded from subsequent analyses. The remaining 11 samples all had $>98 \%$ CG sites detected at $P=0.01$ level, and $>80 \%$ bisulfite conversion rate. The signal intensities were background-adjusted, normalized, and used to calculate beta values using the methylation module. The following CG sites were excluded from analysis: 1) CG sites that were not detected in all samples at $P=0.01$ level; 2) CG sites on $X$ and $Y$ chromosomes; and 3) CG sites assayed by less than five beads in one or more samples. These procedures resulted in 11 samples and 343,023 CG sites for analyses.

For each of the CG sites, the beta values were compared between monocytes and immature $\mathrm{DC}$, and between immature DC and mature DC using paired $t$ tests. Given the small sample size of the methylation array and the importance of the actual methylation level, we used both $P$ values and absolute differences in beta values to determine DMPs. A DMP was defined if $P$ value $\leq 0.05$ and absolute differences in beta values $\geq 0.1$. All microarray data have been deposited to NCBI Gene Expression Omnibus (GSE59796).
To better understand the biological meaning behind the methylome changes, the list of DMPs was imported into Ingenuity Pathway Analysis (Ingenuity Systems, Redwood City, CA) for pathway mapping, gene network detection, and upstream regulator identification. A cutoff of 0.05 was used for statistical significance in IPA analysis.

\section{Bisulfite pyrosequencing}

A total of 200 ng of genomic DNA from each sample was treated with bisulfite using an EZ DNA methylation-Gold Kit (ZYMO research, Irvine, CA, USA) according to the manufacturer's specifications. The bisulfite-treated genomic DNA was amplified by PCR using unbiased nested primers and DNA methylation was measured by quantitative pyrosequencing using a PyroMark Q96 MD (Qiagen, Valencia, CA, USA). The DNA methylation percentage at each CG site was determined using the Pyromark CpG methylation software (Qiagen, Valencia, CA, USA). SssI-treated human genomic DNA was used as $100 \%$ methylation control and human genomic DNA amplified by GenomePlex Complete Whole Genome Amplification (WGA) Kit (Sigma, St. Louis, MO, USA) was used as the nonmethylated DNA control. Primer sequences used for the bisulfite pyrosequencing reactions are shown in Additional file 10, as well as the chromosomal coordinates in the University of California at Santa Cruz February 2009 human genome assembly for each CG site measured. The annealing temperature used for all PCR reactions was between $50^{\circ} \mathrm{C}$ and $55^{\circ} \mathrm{C}$.

\section{Affymetrix microarray expression analysis}

Microarray gene expression profile with Affymetrix hgu133plus2 has been preprocessed by RMA (Robust Multi-array Average) procedure, an algorithm tool to convert the raw probe level data into a normalized expression matrix containing annotated genes [86]. Three groups (immature DC (\#3), mature DC (\#4), and monocyte (\#3)) of our major interest to be compared have biological replicates. To obtain normalized expression measurement, raw intensity values on all corresponding arrays with CEL files were adjusted by background correction, $\log 2$-transformation, normalization across arrays under the rationale of quantile normalization that all distributions are the same, and summarization on single genelevel intensity from combined intensity values in the probe set by making use of median polishing. All pairwise comparisons to test two groups were carried out through a t-test [87] procedure in the genefilter $\mathrm{R}$ package, and a simultaneous multi-group comparison was performed by LIMMA [88]. All analyses were on the basis of Bioconductor and R packages [86]. 


\section{Association of DNA methylation with gene expression}

Microarray data generated by different probes of one gene were averaged and used as the expression at gene-level. The gene-level expression was compared between monocytes and immature DC using paired t tests, and between immature and mature DCs using two-sample $t$ tests. False-discovery rate (FDR) was calculated with the $\mathrm{q}$ value package. Differential expression was considered when $q$ values $\leq 0.05$. The changes in expression levels of differentially expressed genes were then correlated with changes in beta values of DMPs, and Pearson's correlation coefficients were reported for CG sites in the island, shore, shelf, and open sea.

\section{Quantitative PCR}

RNA was isolated from the Qiagen Allprep kit mentioned above, according to manufacturer's instructions. cDNA was synthesized using the Superscript III kit (Life Technologies, Grand Island, NY, USA) using random hexamers. Amplifications were performed using SYBR Green PCR core reagents (Life Technologies, Grand Island, NY, USA), and transcript levels were quantified using an ABI 7900 Sequence Detection Systems (Life Technologies, Grand Island, NY, USA). Mean Ct value of triplicate reaction was normalized against mean $\mathrm{Ct}$ value of GAPDH and/or HPRT. Primer sequences are included in Additional file 11.

\section{Identification of enriched transcription factor binding motifs}

We used a custom 'library' of 1,907 human transcription factor (TF) binding motifs to identify TF motifs enriched in a 'positive' set of sequences (those with DNA methylation changes), compared to a 'negative' set (a matched set of sequences without DNA methylation changes). The library consists of motifs taken from databases such as Transfac [89], JASPAR [90], UniPROBE [91], and FactorBook [92], as well as motifs collected from individual studies such as Jolma et al. [93] and Weirauch et al. [94]. The manuscript describing this motif library is currently in review. We used a 51 base window (25 bases on either side of DMP) to construct all sequence sets. We then estimated the enrichment of each motif using the Pscan [95], which ranks all motifs by $P$ value, based on the average best score of the motif in the sequences of the positive set, compared to the negative set. About 2,000 motifs were tested, so a cutoff of $P<0.000005$ was used (corresponding to a $P$ value of 0.01 , corrected using Bonferroni's conservative method). Nearly identical results were achieved using the HOMER algorithm [96] (data not shown). For example, the top 13 motifs for the monocyte to iDC transition are all AP-1 related (for example, FOS, JUN), all with HOMER $P$ values $<10^{-25}$. Likewise, the top 23 enriched motifs for the $\mathrm{iDC}$ to $\mathrm{mDC}$ transition all contain a GGAA core (for example, BCL11A, SPI, and RELA).

\section{Additional files}

\begin{abstract}
Additional file 1: Prospective isolation of monocyte, immature dendritic cells (iDCs) and mature dendritic cells ( $\mathrm{mDCs}$ ) using fluorescence activated cell sorting (FACS). (A) Schematic showing the protocol used to generate iDCs and mDCs ex vivo from monocytes. (B) Cell populations were purified based on the combination of cell-surface marker expressions defined as follows: monocyte, CD14 ${ }^{+}$; iDCs, HLA-DR $\mathrm{CD}^{-} 3^{-}$; mDCs, HLA-DR ${ }^{\text {high }} \mathrm{CD}^{+} 3^{+}$.
\end{abstract}

Additional file 2: Differentially methylated points (DMPs) identified comparing monocyte to immature dendritic cell (iDC), and comparing iDC to mature dendritic cell $(\mathrm{mDC})$. (A) monocyte $>\mathrm{iDC}$, with the same direction of change in associated genes. (B) monocye $<\mathrm{iDC}$, with the same direction of change in associated genes. (C) monocyte versus iDC, with mixed directions of change in associated genes. (D) iDC $>m D C$, with the same direction of change in associated genes. (E) $i D C<m D C$, with the same direction of change in associated genes.

Additional file 3: Significantly enriched transcription factor (TF) binding sites around differentially methylated points (DMPs). (A) monocyte versus immature dendritic cell (iDC) DMPs. (B) iDC versus mature dendritic cell (mDC) DMPs.

Additional file 4: Ingenuity pathway analyses to identify significantly enriched gene sets and pathways with DNA methylation changes during DC differentiation from monocyte. (A) monocyte $>$ immature dendritic cell (iDC), with the same direction of change in associated genes. (B) monocye $<\mathrm{iDC}$, with the same direction of change in associated genes. (C) monocyte versus iDC, with mixed directions of change in associated genes.

Additional file 5: Ingenuity pathway analyses to identify significantly enriched gene sets and pathways with DNA methylation changes during dendritic cell (DC) maturation. (A) immature dendritic cell $(\mathrm{iDC})>$ mature dendritic cell $(\mathrm{mDC})$, with the same direction of change in associated genes. (B) iDC $<\mathrm{mDC}$, with the same direction of change in associated genes.

Additional file 6: Ingenuity pathway analyses to identify upstream regulator of genes with DNA methylation changes. (A) monocyte versus immature dendritic cell (iDC). (B) iDC versus mature dendritic cell (mDC).

Additional file 7: Correlation of DNA methylation changes with gene expression alterations during dendritic cell (DC) maturation. The changes in expression levels of differentially expressed genes were correlated with changes in beta values of differentially methylated points (DMPs), and Pearson's correlation coefficients were reported for CG sites in the island shore, shelf and open sea, as specified in the figure. When all CG sites combined, $n=46$, Pearson $r=-0.26, P=0.0863$.

Additional file 8: Dynamic changes in expression levels of ten-eleven translocation methylcytosine dioxygenase $2 / 3$ (TET2/3) and DNA-methyltransferases (DNMTs). Gene expression levels of DNMT1, DNMT3A, and DNMT3B (A and C), TET2 and TET3 ( $B$ and D) of one donor among four donors were plotted. Expression level was normalized to GADPH in A and B, to HPRT in C and D. Three technical replicates were used in each condition. Comparisons were made for Day 0 versus Day-1, Day-4 versus Mature Day-1, and Mature Day-1 versus Mature Day-2 using paired t test. ${ }^{*} P<0.05,{ }^{* *} P<0.01$, ${ }^{* * *} P<0.001$, ${ }^{* * * *} P<0.0001$.

Additional file 9: Global changes in $5 \mathrm{mC}$ and $5 \mathrm{hmC}$ during monocyte differentiation into immature dendritic cells (iDCs) and iDC maturation into mature dendritic cells (mDCs). A) 5-mC and B) 5-hmC were measured by ELISA as described in Materials and Methods in the same time course experiment as in Figure 5. C) 5-hmC in fluorescence-activated cell sorting (FACS) purified monocytes, iDCs and mDCs. Paired student t test was used to compare all the different groups. Results are shown as mean \pm SD.

Additional file 10: Primers for bisulfite pyrosequencing and the CpG sites interrogated.

Additional file 11: Primers for qPCR.

\section{Abbreviations}

CDC: conventional dendritic cell; DC: dendritic cell; DMP: differentially methylated points; DNMT: DNA-methyltransferase; ELISA: enzyme-linked 
immunosorbent assay; FACS: fluorescence-activated cell sorting; FDR: false discovery rate; GM-CSF: granulocyte/macrophage colony-stimulating factor; HPRT: hypoxanthine-guanine phosphoribosyltransferase; iDC: immature dendritic cell; IL-4: interleukin 4; LPS: lipopolysaccharide; mDC: mature dendritic cell; TET: ten-eleven translocation methylcytosine dioxygenase; TF: transcription factor; 5-mC: 5-methylcytosine; 5-hmC: 5-hydroxymethylcytosine; IPA: Ingenuity Pathway Analysis; PBMC: Peripheral Blood Mononuclear Cell.

\section{Competing interests}

The authors declare that they have no competing interests.

\section{Authors' contributions}

XZ performed genome-scale microarray processing and statistical analysis; AU performed cell-sorting and extracted DNA/RNA; HKS performed gene-specific DNA methylation, gene expression analysis, and global measurement of $5 \mathrm{mC}$ and $5 \mathrm{hmC}$; MAL assisted in cell sorting; SO analyzed gene expression microarray datasets; HXZ participated in analyzing gene expression microarray datasets; XC performed transcription factor binding motif analysis; MTW participated in transcription factor binding motif analysis; EMJ participated in the design of the experiments; $\mathrm{HJ}$ conceived and designed the experiments and wrote the paper with the assistance of all other authors. All authors read and approved the final manuscript.

\section{Acknowledgements}

We thank Mark Ericksen for laboratory management, the CCHMC FACS facility for assistance in cell sorting, and CCHMC Genetic Variation and Gene Discovery Core Facility for array processing. This work was supported by National Institutes of Health grant to HJ (R21Al101375). EMJ and MAL was supported by Schmidlapp Foundation (Cincinnati Children's Hospital Medical Center) and RO1 CA138617 (NIH/NCl).

\section{Author details}

${ }^{1}$ Division of Human Genetics, Cincinnati Children's Hospital Medical Center, 3333 Burnet Ave, Cincinnati, OH 45229, USA. ²Division of Asthma Research, Cincinnati Children's Hospital Medical Center, 3333 Burnet Ave, Cincinnati, $\mathrm{OH} 45229$, USA. ${ }^{3}$ Division of Human Genetics, Kim Sook Za Children's Hospital Medical Center Research Foundation, 745 JikJi Daero Heung Deok Gu, Cheongju, Chung Buk 361-841, South Korea. ${ }^{4}$ Center for Autoimmune Genomics and Etiology and Division of Biomedical Informatics, Cincinnati Children's Hospital Medical Center, 3333 Burnet Ave, Cincinnati, OH 45229, USA. ${ }^{5}$ Procter \& Gamble Co., Mason Business Center, 8700 S Mason Montgomery Road, Mason, OH 45040, USA. 'SChool of Electronic and Computing Systems, University of Cincinnati, Cincinnati, Ohio 45221, USA. ${ }^{7}$ Division of Immunobiology, Cincinnati Children's Hospital Medical Center, 3333 Burnet Ave, Cincinnati, OH 45229, USA.

Received: 13 May 2014 Accepted: 29 July 2014

Published: 20 August 2014

\section{References}

1. Steinman RM: Decisions about dendritic cells: past, present, and future. Annu Rev Immunol 2012, 30:1-22.

2. Cao H, Verge V, Baron C, Martinache C, Leon A, Scholl S, Gorin NC, Salamero J, Assari S, Bernard J, Lopez M: In vitro generation of dendritic cells from human blood monocytes in experimental conditions compatible for in vivo cell therapy. J Hematother Stem Cell Res 2000, 9:183-194.

3. Randolph GJ, Inaba K, Robbiani DF, Steinman RM, Muller WA: Differentiation of phagocytic monocytes into lymph node dendritic cells in vivo. Immunity 1999, 11:753-761.

4. Lung TL, Saurwein-Teissl M, Parson W, Schonitzer D, Grubeck-Loebenstein B: Unimpaired dendritic cells can be derived from monocytes in old age and can mobilize residual function in senescent T cells. Vaccine 2000, 18:1606-1612.

5. Jonuleit H, Kuhn U, Muller G, Steinbrink K, Paragnik L, Schmitt E, Knop J, Enk $\mathrm{AH}$ : Pro-inflammatory cytokines and prostaglandins induce maturation of potent immunostimulatory dendritic cells under fetal calf serum-free conditions. Eur J Immunol 1997, 27:3135-3142.

6. MacDonald KP, Munster DJ, Clark GJ, Dzionek A, Schmitz J, Hart DN: Characterization of human blood dendritic cell subsets. Blood 2002, 100:4512-4520.
7. Jongbloed SL, Kassianos AJ, McDonald KJ, Clark GJ, Ju X, Angel CE, Chen CJ, Dunbar PR, Wadley RB, Jeet V, Vulink AJ, Hart DN, Radford KJ: Human CD141+ (BDCA-3) + dendritic cells (DCs) represent a unique myeloid DC subset that cross-presents necrotic cell antigens. J Exp Med 2010, 207:1247-1260.

8. Poulin LF, Salio M, Griessinger E, Anjos-Afonso F, Craciun L, Chen JL, Keller AM, Joffre O, Zelenay S, Nye E, Le Moine A, Faure F, Donckier V, Sancho D, Cerundolo V, Bonnet D, Reis e Sousa C: Characterization of human DNGR$1+$ BDCA3+ leukocytes as putative equivalents of mouse CD8alpha + dendritic cells. J Exp Med 2010, 207:1261-1271.

9. Satpathy AT, Wu X, Albring JC, Murphy KM: Re(de)fining the dendritic cell lineage. Nat Immunol 2012, 13:1145-1154.

10. Ji H, Ehrlich LI, Seita J, Murakami P, Doi A, Lindau P, Lee H, Aryee MJ, Irizarry RA, Kim K, Rossi DJ, Inlay MA, Serwold T, Karsunky H, Ho L, Daley GQ, Weissman IL, Feinberg AP: Comprehensive methylome map of lineage commitment from haematopoietic progenitors. Nature 2010, 467:338-342.

11. Deaton AM, Webb S, Kerr AR, Illingworth RS, Guy J, Andrews R, Bird A: Cell type-specific DNA methylation at intragenic CpG islands in the immune system. Genome Res 2011, 21:1074-1086.

12. Bullwinkel J, Ludemann A, Debarry J, Singh PB: Epigenotype switching at the CD14 and CD209 genes during differentiation of human monocytes to dendritic cells. Epigenetics 2011, 6:45-51.

13. Bock C, Beerman I, Lien WH, Smith ZD, Gu H, Boyle P, Gnirke A, Fuchs E, Rossi DJ, Meissner A: DNA methylation dynamics during in vivo differentiation of blood and skin stem cells. Mol Cell 2012, 47:633-647.

14. Ooi SK, Bestor TH: The colorful history of active DNA demethylation. Cell 2008, 133:1145-1148.

15. Gao Y, Chen J, Li K, Wu T, Huang B, Liu W, Kou X, Zhang Y, Huang H, Jiang Y, Yao C, Liu X, Lu Z, Xu Z, Kang L, Chen J, Wang H, Cai T, Gao S: Replacement of Oct4 by Tet1 during iPSC induction reveals an important role of DNA methylation and hydroxymethylation in reprogramming. Cell Stem Cell 2013, 12:453-469.

16. Booth MJ, Ost TW, Beraldi D, Bell NM, Branco MR, Reik W, Balasubramanian S: Oxidative bisulfite sequencing of 5-methylcytosine and 5-hydroxymethylcytosine. Nat Protoc 2013, 8:1841-1851.

17. Ito S, Shen L, Dai Q, Wu SC, Collins LB, Swenberg JA, He C, Zhang Y: Tet proteins can convert 5-methylcytosine to 5-formylcytosine and 5-carboxylcytosine. Science 2011, 333:1300-1303.

18. Klug M, Heinz S, Gebhard C, Schwarzfischer L, Krause SW, Andreesen R, Rehli $M$ : Active DNA demethylation in human postmitotic cells correlates with activating histone modifications, but not transcription levels. Genome Biol 2010, 11:R63.

19. Kalinski P, Muthuswamy $R$, Urban J: Dendritic cells in cancer immunotherapy: vaccines and combination immunotherapies. Expert Rev Vaccines 2013, 12:285-295.

20. Heintzman ND, Hon GC, Hawkins RD, Kheradpour P, Stark A, Harp LF, Ye Z, Lee LK, Stuart RK, Ching CW, Ching KA, Antosiewicz-Bourget JE, Liu H, Zhang X, Green RD, Lobanenkov W, Stewart R, Thomson JA, Crawford GE, Kellis $M$, Ren $B$ : Histone modifications at human enhancers reflect global cell-type-specific gene expression. Nature 2009, 459:108-112.

21. Heintzman ND, Stuart RK, Hon G, Fu Y, Ching CW, Hawkins RD, Barrera LO, Van Calcar S, Qu C, Ching KA, Wang W, Weng Z, Green RD, Crawford GE, Ren $\mathrm{B}$ : Distinct and predictive chromatin signatures of transcriptional promoters and enhancers in the human genome. Nat Genet 2007, 39:311-318.

22. Thurman RE, Rynes E, Humbert R, Vierstra J, Maurano MT, Haugen E, Sheffield NC, Stergachis AB, Wang H, Vernot B, Garg K, John S, Sandstrom R, Bates D, Boatman L, Canfield TK, Diegel M, Dunn D, Ebersol AK, Frum T, Giste E, Johnson AK, Johnson EM, Kutyavin T, Lajoie B, Lee BK, Lee K, London D, Lotakis D, Neph S, et al: The accessible chromatin landscape of the human genome. Nature 2012, 489:75-82.

23. Glasmacher E, Agrawal S, Chang AB, Murphy TL, Zeng W, Vander Lugt B, Khan AA, Ciofani M, Spooner CJ, Rutz S, Hackney J, Nurieva R, Escalante CR, Ouyang W, Littman DR, Murphy KM, Singh H: A genomic regulatory element that directs assembly and function of immune-specific AP-1-IRF complexes. Science 2012, 338:975-980.

24. Becker AM, Michael DG, Satpathy AT, Sciammas R, Singh H, Bhattacharya D: IRF-8 extinguishes neutrophil production and promotes dendritic cell lineage commitment in both myeloid and lymphoid mouse progenitors. Blood 2012, 119:2003-2012. 
25. Ohtsuka H, Sakamoto A, Pan J, Inage S, Horigome S, Ichii H, Arima M, Hatano M, Okada S, Tokuhisa T: Bcl6 is required for the development of mouse CD4+ and CD8alpha + dendritic cells. J Immuno/ 2011, 186:255-263.

26. Hambleton S, Salem S, Bustamante J, Bigley V, Boisson-Dupuis S, Azevedo J, Fortin A, Haniffa M, Ceron-Gutierrez L, Bacon CM, Menon G, Trouillet C, McDonald D, Carey P, Ginhoux F, Alsina L, Zumwalt TJ, Kong XF, Kumararatne D, Butler K, Hubeau M, Feinberg J, Al-Muhsen S, Cant A, Abel L, Chaussabel D, Doffinger R, Talesnik E, Grumach A, Duarte A, et al: IRF8 mutations and human dendritic-cell immunodeficiency. N Engl J Med 2011, 365:127-138.

27. Edelson BT, Kc W, Juang R, Kohyama M, Benoit LA, Klekotka PA, Moon C, Albring JC, Ise W, Michael DG, Bhattacharya D, Stappenbeck TS, Holtzman MJ, Sung SS, Murphy TL, Hildner K, Murphy KM: Peripheral CD103+ dendritic cells form a unified subset developmentally related to CD8alpha + conventional dendritic cells. J Exp Med 2010, 207:823-836.

28. Hildner K, Edelson BT, Purtha WE, Diamond M, Matsushita H, Kohyama M, Calderon B, Schraml BU, Unanue ER, Diamond MS, Schreiber RD, Murphy TL, Murphy KM: Batf3 deficiency reveals a critical role for CD8alpha + dendritic cells in cytotoxic T cell immunity. Science 2008, 322:1097-1100.

29. Poulin LF, Reyal Y, Uronen-Hansson H, Schraml BU, Sancho D, Murphy KM, Hakansson UK, Moita LF, Agace WW, Bonnet D, Reis e Sousa C: DNGR-1 is a specific and universal marker of mouse and human Batf3-dependent dendritic cells in lymphoid and nonlymphoid tissues. Blood 2012, 119:6052-6062.

30. Suzuki S, Honma K, Matsuyama T, Suzuki K, Toriyama K, Akitoyo I, Yamamoto K, Suematsu T, Nakamura M, Yui K, Kumatori A: Critical roles of interferon regulatory factor 4 in CD11bhighCD8alpha- dendritic cell development. Proc Natl Acad Sci U S A 2004, 101:8981-8986.

31. Ghosh HS, Cisse B, Bunin A, Lewis KL, Reizis B: Continuous expression of the transcription factor e2-2 maintains the cell fate of mature plasmacytoid dendritic cells. Immunity 2010, 33:905-916.

32. Schotte R, Nagasawa M, Weijer K, Spits H, Blom B: The ETS transcription factor Spi-B is required for human plasmacytoid dendritic cell development. J Exp Med 2004, 200:1503-1509.

33. Ouaaz F, Arron J, Zheng Y, Choi Y, Beg AA: Dendritic cell development and survival require distinct NF-kappaB subunits. Immunity 2002, $16: 257-270$

34. Vakkila J, Demarco RA, Lotze MT: Coordinate NF-kappaB and STAT1 activation promotes development of myeloid type 1 dendritic cells. Scand J Immunol 2008, 67:260-269.

35. Vorderstrasse BA, Kerkvliet NI: 2,3,7,8-Tetrachlorodibenzo-p-dioxin affects the number and function of murine splenic dendritic cells and their expression of accessory molecules. Toxicol Appl Pharmacol 2001, 171:117-125.

36. Lee JA, Hwang JA, Sung HN, Jeon CH, Gill BC, Youn HJ, Park JH: 2,3,7,8Tetrachlorodibenzo-p-dioxin modulates functional differentiation of mouse bone marrow-derived dendritic cells Downregulation of RelB by 2,3,7,8-tetrachlorodibenzo-p-dioxin. Toxicol Lett 2007, 173:31-40

37. Ruby CE, Funatake CJ, Kerkvliet NI: 2,3,7,8 Tetrachlorodibenzo-p-Dioxin (TCDD) Directly Enhances the Maturation and Apoptosis of Dendritic Cells In Vitro. J Immunotoxicol 2005, 1:159-166.

38. Hao N, Whitelaw ML: The emerging roles of AhR in physiology and immunity. Biochem Pharmacol 2013, 86:561-570.

39. Nguyen NT, Kimura A, Nakahama T, Chinen I, Masuda K, Nohara K, Fujii-Kuriyama Y, Kishimoto T: Aryl hydrocarbon receptor negatively regulates dendritic cell immunogenicity via a kynurenine-dependent mechanism. Proc Natl Acad Sci USA 2010, 107:19961-19966.

40. Klotz L, Dani I, Edenhofer F, Nolden L, Evert B, Paul B, Kolanus W, Klockgether T, Knolle P, Diehl L: Peroxisome proliferator-activated receptor gamma control of dendritic cell function contributes to development of CD4+ T cell anergy. J Immunol 2007, 178:2122-2131

41. Szatmari I, Torocsik D, Agostini M, Nagy T, Gurnell M, Barta E, Chatterjee K, Nagy L: PPARgamma regulates the function of human dendritic cells primarily by altering lipid metabolism. Blood 2007, 110:3271-3280.

42. Majai G, Gogolak P, Ambrus C, Vereb G, Hodrea J, Fesus L, Rajnavolgyi E: PPARgamma modulated inflammatory response of human dendritic cell subsets to engulfed apoptotic neutrophils. J Leukoc Biol 2010, 88:981-991.

43. Szatmari I, Rajnavolgyi E, Nagy L: PPARgamma, a lipid-activated transcription factor as a regulator of dendritic cell function. Ann N Y Acad Sci 2006, 1088:207-218

44. Park D, Lapteva N, Seethammagari M, Slawin KM, Spencer DM: An essential role for Akt1 in dendritic cell function and tumor immunotherapy. Nat Biotechnol 2006, 24:1581-1590.
45. Otterbein LE, Choi AM: Heme oxygenase: colors of defense against cellular stress. Am J Physiol Lung Cell Mol Physiol 2000, 279:L1029-L1037.

46. Chauveau C, Remy S, Royer PJ, Hill M, Tanguy-Royer S, Hubert FX, Tesson L, Brion R, Beriou G, Gregoire M, Josien R, Cuturi MC, Anegon I: Heme oxygenase-1 expression inhibits dendritic cell maturation and proinflammatory function but conserves IL-10 expression. Blood 2005, 106:1694-1702.

47. Tardif V, Riquelme SA, Remy S, Carreno LJ, Cortes CM, Simon T, Hill M, Louvet C, Riedel CA, Blancou P, Bach JM, Chauveau C, Bueno SM, Anegon I, Kalergis AM: Carbon monoxide decreases endosome-lysosome fusion and inhibits soluble antigen presentation by dendritic cells to T cells. Eur $\mathrm{J}$ Immunol 2013, 43:2832-2844.

48. Dhodapkar KM, Banerjee D, Connolly J, Kukreja A, Matayeva E, Veri MC, Ravetch JV, Steinman RM, Dhodapkar MV: Selective blockade of the inhibitory Fcgamma receptor (FcgammaRIIB) in human dendritic cells and monocytes induces a type I interferon response program. J Exp Med 2007, 204:1359-1369.

49. Heystek HC, Thierry AC, Soulard P, Moulon C: Phosphodiesterase 4 inhibitors reduce human dendritic cell inflammatory cytokine production and Th1-polarizing capacity. Int Immunol 2003, 15:827-835.

50. Clayton A, Harris CL, Court J, Mason MD, Morgan BP: Antigen-presenting cell exosomes are protected from complement-mediated lysis by expression of CD55 and CD59. Eur J Immunol 2003, 33:522-531.

51. Mezger M, Wozniok I, Blockhaus C, Kurzai O, Hebart H, Einsele H, Loeffler J: Impact of mycophenolic acid on the functionality of human polymorphonuclear neutrophils and dendritic cells during interaction with Aspergillus fumigatus. Antimicrob Agents Chemother 2008, 52:2644-2646.

52. Zheng Y, Manzotti CN, Liu M, Burke F, Mead KI, Sansom DM: CD86 and CD80 differentially modulate the suppressive function of human regulatory T cells. J Immunol 2004, 172:2778-2784.

53. Orabona C, Grohmann U, Belladonna ML, Fallarino F, Vacca C, Bianchi R, Bozza S, Volpi C, Salomon BL, Fioretti MC, Romani L, Puccetti P: CD28 induces immunostimulatory signals in dendritic cells via CD80 and CD86. Nat Immunol 2004, 5:1134-1142.

54. Schwarz AM, Banning-Eichenseer U, Seidel K, Mauz-Korholz C, Korholz D, Staege MS: Impact of interleukin-10 on phenotype and gene expression during early monocyte differentiation into dendritic cells. Anticancer Res 2013, 33:4791-4798.

55. De Smedt T, Van Mechelen M, De Becker G, Urbain J, Leo O, Moser M: Effect of interleukin-10 on dendritic cell maturation and function. Eur J Immunol 1997, 27:1229-1235.

56. Dieu MC, Vanbervliet B, Vicari A, Bridon JM, Oldham E, Ait-Yahia S, Briere F, Zlotnik A, Lebecque S, Caux C: Selective recruitment of immature and mature dendritic cells by distinct chemokines expressed in different anatomic sites. J Exp Med 1998, 188:373-386.

57. Sallusto F, Schaerli P, Loetscher P, Schaniel C, Lenig D, Mackay CR, Qin S, Lanzavecchia A: Rapid and coordinated switch in chemokine receptor expression during dendritic cell maturation. Eur J Immunol 1998, 28:2760-2769.

58. Riol-Blanco L, Sanchez-Sanchez N, Torres A, Tejedor A, Narumiya S, Corbi AL, Sanchez-Mateos P, Rodriguez-Fernandez JL: The chemokine receptor CCR7 activates in dendritic cells two signaling modules that independently regulate chemotaxis and migratory speed. J Immunol 2005, 174:4070-4080.

59. Li K, Fazekasova H, Wang N, Sagoo P, Peng Q, Khamri W, Gomes C, Sacks SH, Lombardi G, Zhou W: Expression of complement components, receptors and regulators by human dendritic cells. Mol Immunol 2011 48:1121-1127.

60. Doi A, Park IH, Wen B, Murakami P, Aryee MJ, Irizarry R, Herb B, Ladd-Acosta C, Rho J, Loewer S, Miller J, Schlaeger T, Daley GQ, Feinberg AP: Differential methylation of tissue- and cancer-specific CpG island shores distinguishes human induced pluripotent stem cells, embryonic stem cells and fibroblasts. Nat Genet 2009, 41:1350-1353.

61. Irizarry RA, Ladd-Acosta C, Wen B, Wu Z, Montano C, Onyango P, Cui H, Gabo K, Rongione M, Webster M, Ji H, Potash JB, Sabunciyan S, Feinberg AP: The human colon cancer methylome shows similar hypo- and hypermethylation at conserved tissue-specific CpG island shores. Nat Genet 2009, 41:178-186.

62. Robbins SH, Walzer T, Dembele D, Thibault C, Defays A, Bessou G, Xu H, Vivier E, Sellars M, Pierre P, Sharp FR, Chan S, Kastner P, Dalod M: Novel insights into the relationships between dendritic cell subsets in human and mouse revealed by genome-wide expression profiling. Genome Biol 2008, 9:R17. 
63. Fujiki K, Shinoda A, Kano F, Sato R, Shirahige K, Murata M: PPARgamma-induced PARylation promotes local DNA demethylation by production of 5-hydroxymethylcytosine. Nat Commun 2013, 4:2262.

64. D'Angelo R, Aresta S, Blangy A, Del Maestro L, Louvard D, Arpin M: Interaction of ezrin with the novel guanine nucleotide exchange factor PLEKHG6 promotes RhoG-dependent apical cytoskeleton rearrangements in epithelial cells. Mol Biol Cell 2007, 18:4780-4793.

65. Asiedu M, Wu D, Matsumura F, Wei Q: Centrosome/spindle pole-associated protein regulates cytokinesis via promoting the recruitment of MyoGEF to the central spindle. Mol Biol Cell 2009, 20:1428-1440.

66. Wu D, Asiedu M, Adelstein RS, Wei Q: A novel guanine nucleotide exchange factor MyoGEF is required for cytokinesis. Cell Cycle 2006 5:1234-1239.

67. Chow A, Toomre D, Garrett W, Mellman I: Dendritic cell maturation triggers retrograde $\mathrm{MHC}$ class II transport from lysosomes to the plasma membrane. Nature 2002, 418:988-994.

68. Boes M, Bertho N, Cerny J, Op den Brouw M, Kirchhausen T, Ploegh H: T cells induce extended class II MHC compartments in dendritic cells in a Toll-like receptor-dependent manner. J Immunol 2003, 171:4081-4088.

69. Evans R, Patzak I, Svensson L, De Filippo K, Jones K, McDowall A, Hogg N: Integrins in immunity. J Cell Sci 2009, 122:215-225.

70. Katakai T, Habiro K, Kinashi T: Dendritic cells regulate high-speed interstitial T cell migration in the lymph node via LFA-1/ICAM-1. J Immuno/ 2013, 191:1188-1199.

71. Klug M, Schmidhofer S, Gebhard C, Andreesen R, Rehli M: 5Hydroxymethylcytosine is an essential intermediate of active DNA demethylation processes in primary human monocytes. Genome Biol 2013, 14:R46.

72. Kallin EM, Rodriguez-Ubreva J, Christensen J, Cimmino L, Aifantis I, Helin K, Ballestar E, Graf T: Tet2 facilitates the derepression of myeloid target genes during CEBPalpha-induced transdifferentiation of pre-B cells. $\mathrm{Mol}$ Cell 2012, 48:266-276.

73. Kaneda M, Okano M, Hata K, Sado T, Tsujimoto N, Li E, Sasaki H: Essential role for de novo DNA methyltransferase Dnmt3a in paternal and maternal imprinting. Nature 2004, 429:900-903.

74. Trowbridge JJ, Orkin SH: Dnmt3a silences hematopoietic stem cell self-renewal. Nat Genet 2012, 44:13-14.

75. Challen GA, Sun D, Jeong M, Luo M, Jelinek J, Berg JS, Bock C, Vasanthakumar A, Gu H, Xi Y, Liang S, Lu Y, Darlington GJ, Meissner A, Issa JP, Godley LA, Li W, Goodell MA: Dnmt3a is essential for hematopoietic stem cell differentiation. Nat Genet 2012, 44:23-31.

76. Rhee I, Bachman KE, Park BH, Jair KW, Yen RW, Schuebel KE, Cui H, Feinberg AP, Lengauer C, Kinzler KW, Baylin SB, Vogelstein B: DNMT1 and DNMT3b cooperate to silence genes in human cancer cells. Nature 2002, 416:552-556.

77. Metivier R, Gallais R, Tiffoche C, Le Peron C, Jurkowska RZ, Carmouche RP, Ibberson D, Barath P, Demay F, Reid G, Benes V, Jeltsch A, Gannon F, Salbert G: Cyclical DNA methylation of a transcriptionally active promoter. Nature 2008, 452:45-50.

78. Chen CC, Wang KY, Shen CK: The mammalian de novo DNA methyltransferases DNMT3A and DNMT3B are also DNA 5-hydroxymethylcytosine dehydroxymethylases. J Biol Chem 2012, 287:33116-33121.

79. Chen CC, Wang KY, Shen CK: DNA 5-methylcytosine demethylation activities of the mammalian DNA methyltransferases. J Biol Chem 2013, 288:9084-9091.

80. Frikeche J, Clavert A, Delaunay J, Brissot E, Gregoire M, Gaugler B, Mohty M: Impact of the hypomethylating agent 5-azacytidine on dendritic cells function. Exp Hematol 2011, 39:1056-1063.

81. Di Ruscio A, Ebralidze AK, Benoukraf T, Amabile G, Goff LA, Terragni J, Figueroa ME, De Figueiredo Pontes LL, Alberich-Jorda M, Zhang P, Wu M, D'Alò F, Melnick A, Leone G, Ebralidze KK, Pradhan S, Rinn JL, Tenen DG: DNMT1-interacting RNAs block gene-specific DNA methylation. Nature 2013, 503:371-376

82. Thurner B, Roder C, Dieckmann D, Heuer M, Kruse M, Glaser A, Keikavoussi $P$, Kampgen E, Bender A, Schuler G: Generation of large numbers of fully mature and stable dendritic cells from leukapheresis products for clinical application. J Immunol Methods 1999, 223:1-15.

83. Bender A, Sapp M, Schuler G, Steinman RM, Bhardwaj N: Improved methods for the generation of dendritic cells from nonproliferating progenitors in human blood. J Immunol Methods 1996, 196:121-135.
84. Dauer M, Schad K, Herten J, Junkmann J, Bauer C, Kiefl R, Endres S, Eigler A: FastDC derived from human monocytes within $48 \mathrm{~h}$ effectively prime tumor antigen-specific cytotoxic T cells. J Immunol Methods 2005, 302:145-155.

85. Salcedo M, Bercovici N, Taylor R, Vereecken P, Massicard S, Duriau D, Vernel-Pauillac F, Boyer A, Baron-Bodo V, Mallard E, Bartholeyns J, Goxe B, Latour N, Leroy S, Prigent D, Martiat P, Sales F, Laporte M, Bruyns C, Romet-Lemonne JL, Abastado JP, Lehmann F, Velu T: Vaccination of melanoma patients using dendritic cells loaded with an allogeneic tumor cell lysate. Cancer Immunol Immunother 2006, 55:819-829.

86. Irizarry RA, Hobbs B, Collin F, Beazer-Barclay YD, Antonellis KJ, Scherf U, Speed TP: Exploration, normalization, and summaries of high density oligonucleotide array probe level data. Biostatistics 2003, 4:249-264.

87. Welch BL: On the comparison of several mean values: an alternative approach. Biometrika 1951, 38:330-336.

88. Smyth GK: Limma: Linear Models for Microarray Data. In Bioinformatics and Computational Biology Solutions using $R$ and Bioconductor. Edited by Gentleman R, Carey V, Dudoit S, Irizarry R, Huber W. New York: Springer; 2005:397-420.

89. Matys V, Kel-Margoulis OV, Fricke E, Liebich I, Land S, Barre-Dirrie A, Reuter I, Chekmenev D, Krull M, Hornischer K, Voss N, Stegmaier P, Lewicki-Potapov $B$, Saxel $H$, Kel AE, Wingender E: TRANSFAC and its module TRANSCompel: transcriptional gene regulation in eukaryotes. Nucleic Acids Res 2006, 34:D108-D110.

90. Mathelier A, Zhao X, Zhang AW, Parcy F, Worsley-Hunt R, Arenillas DJ, Buchman S, Chen CY, Chou A, lenasescu H, Lim J, Shyr C, Tan G, Zhou M, Lenhard B, Sandelin A, Wasserman WW: JASPAR 2014: an extensively expanded and updated open-access database of transcription factor binding profiles. Nucleic Acids Res 2014, 42:D142-D147.

91. Robasky K, Bulyk ML: UniPROBE, update 2011: expanded content and search tools in the online database of protein-binding microarray data on protein-DNA interactions. Nucleic Acids Res 2011, 39:D124-D128.

92. Wang J, Zhuang J, lyer S, Lin XY, Greven MC, Kim BH, Moore J, Pierce BG, Dong X, Virgil D, Birney E, Hung JH, Weng Z: Factorbook.org: a Wiki-based database for transcription factor-binding data generated by the ENCODE consortium. Nucleic Acids Res 2013, 41:D171-D176.

93. Jolma A, Yan J, Whitington T, Toivonen J, Nitta KR, Rastas P, Morgunova E, Enge M, Taipale M, Wei G, Palin K, Vaquerizas JM, Vincentelli R, Luscombe NM, Hughes TR, Lemaire P, Ukkonen E, Kivioja T, Taipale J: DNA-binding specificities of human transcription factors. Cell 2013, 152:327-339.

94. Weirauch MT, Cote A, Norel R, Annala M, Zhao Y, Riley TR, Saez-Rodriguez J, Cokelaer T, Vedenko A, Talukder S, DREAM5 Consortium, Bussemaker HJ, Morris QD, Bulyk ML, Stolovitzky G, Hughes TR: Evaluation of methods for modeling transcription factor sequence specificity. Nat Biotechnol 2013, 31:126-134.

95. Zambelli F, Pesole G, Pavesi G: Pscan: finding over-represented transcription factor binding site motifs in sequences from co-regulated or co-expressed genes. Nucleic Acids Res 2009, 37:W247-W252.

96. Heinz S, Benner C, Spann N, Bertolino E, Lin YC, Laslo P, Cheng JX, Murre C, Singh H, Glass CK: Simple combinations of lineage-determining transcription factors prime cis-regulatory elements required for macrophage and $B$ cell identities. Mol Cell 2010, 38:576-589.

\section{doi:10.1186/1756-8935-7-21}

Cite this article as: Zhang et al:: DNA methylation dynamics during ex vivo differentiation and maturation of human dendritic cells. Epigenetics \& Chromatin 2014 7:21. 